\section{Interaction between RAAS inhibitors and ACE2 in the context of COVID-19}

\author{
Jean-Jacques Mourad (10) and Bernard I. Levy
}

In the Comment article by Zheng and colleagues (COVID-19 and the cardiovascular system. Nat. Rev. Cardiol. https://doi.org/ $10.1038 /$ s41569-020-0360-5 (2020)) $)^{1}$, the crucial role of angiotensin-converting enzyme 2 (ACE2) in severe acute respiratory syndrome coronavirus 2 (SARS-CoV-2) infection, which causes coronavirus disease 2019 (COVID-19), was highlighted. ACE2 is a membrane-bound aminopeptidase that cleaves angiotensin I and angiotensin II into the angiotensin-(1-9) and angiotensin-(1-7) peptides. Several studies support the existence of a cardiovascular-protective ACE2angiotensin-(1-7)-Mas receptor axis ${ }^{2}$. ACE2 is overexpressed in heart failure, arterial hypertension and diabetes mellitus ${ }^{3}$. Moreover, ACE2 has been identified as a functional receptor for the entry of coronaviruses generally, and SARS-CoV-2 specifically, into host cells ${ }^{4}$.

Given that most of the severe forms of COVID-19 have occurred in elderly patients with cardiovascular comorbidities, Zheng and colleagues speculate about the influence of chronic treatment with blockers of the renin-angiotensin-aldosterone system (RAAS) on the severity of the infection, stating that "ACE2 levels can be increased by the use of renin-angiotensin-aldosterone system inhibitors" ${ }^{\text {. }}$. Consequently, the authors suggest that "the safety and potential effects of antihypertension therapy with ACE inhibitors or angiotensin-receptor blockers in patients with COVID-19 should be carefully considered".

We wish to clarify that different RAAS inhibitors have different effects on ACE2 levels. By acting at different levels of the system, RAAS inhibitors result in heterogeneous effects on the peptides and enzymes involved. Whereas angiotensin-receptor blockers and mineralocorticoid-receptor blockers have been shown to increase the levels of ACE2 expression and activity in various experimental and clinical models ${ }^{5,6}$, administration of ACE inhibitors increased cardiac Ace 2 mRNA levels but had no effect on ACE2 activity in experimental models ${ }^{7,8}$. In addition, in an animal model of diabetic nephropathy, the chronic administration of aliskiren (a direct inhibitor of renin) was associated with a reduction in ACE2 expression'. For these reasons, we believe that chronic treatment with ACE inhibitors has no reason to influence the course of SARS-CoV-2 infection. By contrast, the use of angiotensin-receptor blockers or mineralocorticoid-receptor blockers might warrant caution and further analysis in the context of SARS-CoV-2 infection. The reduced expression of ACE2 with aliskiren treatment could be an interesting option in the context of SARS-CoV-2 infection that requires further investigation.

There is a reply to this letter by Zheng, Y. Y. et al. Nat. Rev. Cardiol. https://doi.org/10.1038/ s41569-020-0369-9 (2020).

Jean-Jacques Mourad (D) ${ }^{凶}$ and Bernard I. Levy ${ }^{2}$ 'ESH Excellence Centre, Internal Medicine, Groupe hospitalier Paris Saint-Joseph, Paris, France. IInsermU970, PARRC, Hôpital Lariboisière, Paris, France. 凶e-mail: jjmourad@hpsj.fr https://doi.org/10.1038/s41569-020-0368-x
We thank Mourad and Levy for their constructive Correspondence (Interaction between RAAS inhibitors and ACE2 in the context of COVID-19. Nat. Rev. Cardiol. https://doi.org/ 10.1038/s41569-020-0368-x (2020)) $)^{1}$ on our Comment article (COVID-19 and the cardiovascular system. Nat. Rev. Cardiol. https://doi. org/10.1038/s41569-020-0360-5 (2020)) $)^{2}$. We agree with their comments and acknowledge that different renin-angiotensin-aldosterone system (RAAS) inhibitors have different effects on angiotensin-converting enzyme 2 (ACE2) levels. Ferrario and colleagues ${ }^{3}$ reported that administration of either ACE inhibitors or angiotensin-receptor blockers (ARBs) increased the levels of Ace 2 mRNA in Lewis rats compared with rats receiving placebo. In particular, cardiac levels of Ace 2 mRNA increased by 4.7 -fold or 2.8 -fold in rats given either lisinopril (an ACE inhibitor) or losartan (an ARB), respectively. Furthermore, the researchers found that losartan treatment, but not lisinopril
1. Zheng, Y. Y., Ma, Y. T., Zhang, J. Y. \& Xie, X COVID-19 and the cardiovascular system. Nat Rev. Cardiol. https://doi.org/10.1038/s41569-020-0360-5 (2020)

2. Patel, V. B., Zhong, J. C., Grant, M. B. \& Oudit, G. Y. Role of the ACE2/angiotensin 1-7 axis of the reninangiotensin system in heart failure. Circ. Res. 118 1313-1326 (2016)

3. Te Riet, L., van Esch, J. H., Roks, A. J., van den Meiracker, A. H. \& Danser, A. H. Hypertension: renin-angiotensin-aldosterone system alterations. Circ Res 116 960-975 (2015)

4. Hoffmann, M. et al. SARS-CoV-2 cell entry depends on ACE2 and TMPRSS2 and is blocked by a clinically proven protease inhibitor. Cell https://doi.org/10.1016/ cell.2020.02.052 (2020).

Keidar, S, et al. Mineralocorticoid receptor blocker increases angiotensin-converting enzyme 2 activity in congestive heart failure patients. Circ. Res. 97, 946-953 (2005).

6. Zhong, J. C. et al. Telmisartan attenuates aortic hypertrophy in hypertensive rats by the modulation of ACE2 and profilin-1 expression. Regul. Pept. 166, 90-97 (2011)

7. Ferrario, C. M. et al. Effect of angiotensin-converting enzyme inhibition and angiotensin II receptor blockers on cardiac angiotensin-converting enzyme 2. Circulation 111, 2605-2610 (2005).

8. Tipnis, S. R. et al. A human homolog of angiotensinconverting enzyme: cloning and functional expression as a captopril-insensitive carboxypeptidase. J. Biol. Chem. 275, 33238-33243 (2000).

9. Ding, W. et al. Aliskiren inhibits angiotensin II/ angiotensin 1-7 (Ang II/Ang 1-7) signal pathway in rats with diabetic nephropathy [Chinese]. Xi Bao Yu Fen Zi Mian Yi Xue Za Zhi 34, 891-895 (2018).

\section{Competing interests}

J.-J.M. has received fees for consultancy from Mylan, Pfizer and Servier. B.I.L. has received grants and personal fees from Bayer, Roche and Servier.

\title{
Reply to: 'Interaction between RAAS inhibitors and ACE2 in the context of COVID-19'
}

Ying-Ying Zheng (D), Yi-Tong Ma®D, Jin-Ying Zhang (D) and Xiang Xie (1)

treatment, increased ACE2 activity compared with placebo. However, the researchers did not shed light on the mechanisms that might account for these differences. Nevertheless, $\mathrm{Li}$ and colleagues ${ }^{4}$ found that treatment with captopril (an ACE inhibitor) can significantly increase ACE2 protein expression in rats with acute lung injury. Furthermore, Wöstenvan Asperen and colleagues ${ }^{5}$ reported that, in a rat model of acute respiratory distress syndrome, ACE activity and angiotensin II expression are increased, whereas ACE2 activity and angiotensin-(1-7) levels are reduced.

The protective effects of the ACE2angiotensin-(1-7)-Mas receptor axis are primarily mediated by reductions in angiotensin II level ${ }^{6}$. Both ACE inhibitors and ARBs can reduce angiotensin II levels ${ }^{7}$. The former inhibit the substrate of angiotensin II generation, and the latter directly inhibit the conversion of angiotensin I to angiotensin II. Therefore, RAAS inhibitors, including ACE 